\title{
Consequences of Working in Eldercare during Organizational Changes and Cut Backs While Education and Clinical Supervision Was Provided: A Mixed Methods Study
}

\author{
Birgitta Fläckman', Kirsti Skovdahl², Ingegerd Fagerberg1,3, Mona Kihlgren4, \\ Annica Kihlgren ${ }^{*}$ \\ ${ }^{1}$ Department of Health Care Sciences, Ersta Sköndal University College, Stockholm, Sweden \\ ${ }^{2}$ Faculty for Health Sciences, Buskerud and Vestfold University College, Drammen, Norway \\ ${ }^{3}$ Department of Neurobiology, Care Sciences and Society, Karolinska Institute, Stockholm, Sweden \\ ${ }^{4}$ Centre for Caring Sciences, Örebro University Hospital, Örebro, Sweden \\ ${ }^{5}$ School of Health and Medical Sciences, Örebro University, Örebro, Sweden \\ Email: Birgitta.Flackman@esh.se, Kirsti.Skovdahl@hbv.no, Ingegerd.Fagerberg@esh.se, \\ Mona.Kihlgren@telia.com, ${ }^{*}$ Annica.Kihlgren@oru.se
}

Received 24 August 2015; accepted 22 September 2015; published 25 September 2015

Copyright (C) 2015 by authors and Scientific Research Publishing Inc.

This work is licensed under the Creative Commons Attribution International License (CC BY). http://creativecommons.org/licenses/by/4.0/

(c) (i) Open Access

\section{Abstract}

Background: Reorganization and downsizing can disrupt a competent staff and conflicts can arise between what the employee is being asked to do and their knowledge and competences. Reduced job satisfaction among nursing home staff with increased workload and strain can occur. Aim and Objectives: The aim was to investigate the organizational climate and prevalence of burnout symptoms among caregivers over time in three Swedish nursing homes (NH I-III) undergoing organizational changes, while education and clinical supervision were provided. Design: The study design combines qualitative and quantitative methods in a longitudinal two-year follow-up project in NH I-III. Methods: Support through education and clinical supervision was provided for caregivers only at NH I and NH II. At NH I-III caregiver self-assessments and interviews were completed and analysed three different times. Results: NH I revealed improvement and increased innovation over time, while NH II showed a decline with no ability to implement new knowledge. NH III retained a more status quo. Conclusions: Organizational changes and cutbacks, occurring at different times, appeared to cause major stress and frustration among the three personnel groups. They felt

${ }^{*}$ Corresponding author.

How to cite this paper: Fläckman, B., Skovdahl, K., Fagerberg, I., Kihlgren, M. and Kihlgren, A. (2015) Consequences of Working in Eldercare during Organizational Changes and Cut Backs While Education and Clinical Supervision Was Provided: A Mixed Methods Study. Open Journal of Nursing, 5, 813-827. http://dx.doi.org/10.4236/ojn.2015.59086 
guilty about not meeting their perceived obligations, seemed to have lost pride in their work but kept struggling. The changes seemed to over-shadow attempts to improve working conditions through education and clinical supervision initially. Implications for practice: It will be important to learn from reorganizations and the consequences they will have for the staff and quality of care. Important topics for future research are to study financial cutbacks and changes in organizational processes in care of older people to be able to develop a more person centered care for older people.

\section{Keywords}

Nursing Home, Organizational Climate and Burnout, Education and Clinical Supervision, Cutbacks and Organizational Changes

\section{Introduction}

The focus in this study is to investigate through caregivers' self- assessments and experiences, the organizational climate and burnout relative to changes and cut backs in elder care; while education and clinical supervision was provided. In the last decades, the care of older people has increasingly come to be viewed as a primarily public matter in Sweden. Divergent and opposite views to mobilise a reorganization of public services and identities of workers have been discussed in the Nordic countries [1] [2]. When interviewing employees at different nursing homes, they regarded their job as meaningful and were proud of their work but revealed that a moral uneasiness existed between the care they were able to provide and what they would like to provide [3]. Häggström et al. [4] have also found mixed feelings toward work. The caregivers experienced a committed relationship to older people but felt guilty when organizational structures forced them to rush their daily care and did not allow enough time for each person. It is difficult for caregivers to balance all demands successfully and Suhonen et al. [5] as well as Fagerberg and Engström [6] suggest that key aspects are ethical discussions within their work.

Organizational changes have been addressed as a factor that prevents learning interventions in the care of older people [7] and this is unfortunate, considering the importance of development in the care of older people. Within the context of nursing health care, supervision has been viewed as a valuable means of supporting and developing professional practice [8] and one way of recruiting and keeping personnel aimed at developing professional competence and personal identity [9]. Another way to develop staff members' lack of formal competence can be with e-learning and e-assessment [10]. Furthermore, ethical dilemmas are present in almost every nursing care situation and clinical supervision makes it possible for reflection on these ethical dilemmas [11] resulting in a process leading to increased quality of care [12].

As people live longer nowadays, they consume an increasing amount of various forms of health care. At the same time, the financial resources in society are decreasing, necessitating efficient usage of health care resources [13] [14]. Among those working in elder care, licensed practical nurses (LPNs) and nurse's aides (NAs) make up the largest group, with registered nurses (RNs) numbering only a few [14] [15]. Weak leadership is thought to be a prominent problem in municipal care of the old [6] [16]. There is also a problem with illness absenteeism and staff turnover, which have increased markedly during recent years. In municipal health care, a lack of welleducated personnel and difficulties in retaining personnel are well-known facts that have an immense impact [17].

Burnout is most commonly defined as a syndrome that includes feelings of emotional exhaustion, depersonalization and reduced personal accomplishment [18]. In Sweden, burnout has been cited as one of the major causes of the sharp increase in long-term disability [19]. When meaningfulness and manageability are not balanced, feelings of fatigue and symptoms of burnout appear. Likewise, high job involvement plays paradoxically a part in burnout [20].

According to Ekvall [21], the work climate is regarded as an attribute of the organization, such that attitudes, feelings and behaviours characterize life in the organization. These exist, independent of the perceptions and understandings held by organization members. The work climate influences organizational processes such as problem-solving, decision-making, communication, co-ordination and control [21] [22]. In times of downsizing and reorganization, challenges emerge regarding ways of keeping and motivating those affected [23]. 
The literature review shows that changes in the health care system exist today and has done so previously as well. Changes will always likely be present in elder care and necessary if they contribute to the development of health care in a positive manner. However, little is known about how caregivers are influenced by these changes and cutbacks in the elder care context during clinical supervision. Presumably these changes can undermine caregivers' ability to do good work and to feel good about their work. It therefore seems important to focus on caregivers' experiences when threats of organizational change and closing of facilities occur during clinical supervision.

The aim of the present study was to investigate the organizational climate and prevalence of burnout symptoms among caregivers over time in three Swedish nursing homes undergoing organizational changes, while education and clinical supervision was provided. This study addressed a research question: What are the consequences for the caregivers when organizational changes are a fact?

\section{Methods and Material}

The present study is part of a two-year, annual follow-up, longitudinal project in three Swedish municipal nursing homes of older people (NH I, NH II and NH III). At the outset of the project, promises were made that no organizational changes were planned. Despite this, as a result of political decisions, administrative reorganization and personnel reductions on all shifts were instituted at all three of the NHs, though at different times during the two-year period. At the onset of the present study a quantitative approach was chosen in order to explore organizational climate and prevalence of burnout among caregivers in three nursing homes. Due to the organizational changes that led to subjects dropping out, we decided to include interview data with the same focus from the caregivers working at the involved NHs.

\subsection{Design and Settings}

The present study has combined quantitative and qualitative methods to facilitate acquisition of knowledge and improved understanding. Certain questions required a mixed methods approach; mixed-method research can expand and improve analytical power in studies [24]. Organizational climate and prevalence of burnout symptoms were studied at the group level at three different nursing homes. After collection of the initial baseline data at NH I, NH II and NH III a two-year support through education and clinical supervision started at NH I and NH II. Caregivers were able to request the educational topics and could give their input regarding the approach taken to the education and clinical supervision. A voluntary training program was offered about once a month and delivered by physicians and nurse specialists during the two years. Caregivers sought more knowledge about different diseases, as well as additional training in communication, seeking literature, team cooperation, and conflict management. This staff support is further described by Fläckman et al. [25].

In an effort to be more comprehensive, the NHs were followed over a two years period. NH I, with 40 residents, was situated in a municipality with a population of over 100,000. NH II and NH III, with 40 and 52 residents respectively, were located in a municipality with 20,000 inhabitants. Several residents had dementia diagnoses and multiple diseases, some in advanced stages including behavioural and psychiatric symptoms of dementia (BPSD). Each of the NHs had one RN and the total ratio, including LPNs and NAs, was 1.0 staff member per bed (including night staff). The staff members were distributed so as to cover all the shifts.

The time frame for the announcement of the politicians' decisions for reorganization and financial cutbacks at the respective NHs is presented in Figure 1. For example, nine RNs from NH I who resigned were replaced by LPNs. Additionally, a simultaneous reduction in the number of employees and an increase in the number of residents took place at NH II, and when personnel were absent, they were not replaced. NH III was still in its original form at the end of the study, but the number of residents and personnel had decreased markedly.

\subsection{Sample}

The personnel at the three NHs gave their informed consent to participate in the study. The Regional Research Ethics Committees (§ 803/99, § 00-070) approved this project. Information was given verbally that participation was voluntary, confidentiality was guaranteed and that participants had the right to leave the study at any time without giving a reason. The caregivers who volunteered to participate, performed the self-assessments and were interviewed are further presented in Table 1, Table 2. The participating caregivers varied at the three data collection points, but no new caregivers were included during the study time. Caregivers dropped out due to illness, personnel turnover, inability to respond for personal reasons and undefined reasons. 
Table 1. Caregivers at NH I-III and their response rate on CCQ with mean values and standard deviations (SD) versus normative data on innovative and stagnated organizations according to Ekvall [22].

\begin{tabular}{|c|c|c|c|c|c|c|c|c|c|c|}
\hline & & \multicolumn{3}{|c|}{ I } & \multicolumn{3}{|c|}{ II } & \multicolumn{3}{|c|}{ III } \\
\hline & & & 12 & 24 & & 12 & 24 & & 12 & 24 \\
\hline & & Baseline & month & month & Baseline & month & month & Baseline & month & month \\
\hline Caregiver & & $\mathrm{n}=19$ & $\mathrm{n}=13$ & $\mathrm{n}=12$ & $\mathrm{n}=16$ & $\mathrm{n}=13$ & $\mathrm{n}=13$ & $\mathrm{n}=11$ & $\mathrm{n}=14$ & $\mathrm{n}=11$ \\
\hline RNs and LPNs & & $1 / 15$ & $1 / 11$ & $0 / 11$ & $0 / 7$ & $0 / 6$ & $0 / 7$ & $0 / 2$ & $0 / 1$ & $0 / 2$ \\
\hline NAs and SS & & $2 / 0$ & $1 / 0$ & $1 / 0$ & $8 / 1$ & $6 / 1$ & $6 / 0$ & $9 / 0$ & $13 / 0$ & 9 \\
\hline Female/male & & $17 / 1$ & $12 / 1$ & $10 / 2$ & $15 / 1$ & $12 / 1$ & $11 / 2$ & $11 / 0$ & $14 / 0$ & $11 / 0$ \\
\hline \multirow[t]{4}{*}{ Age (years) } & $18-34$ & 5 & 2 & 2 & 4 & & 2 & 2 & 2 & 1 \\
\hline & $35-44$ & 8 & 7 & 7 & 8 & 7 & 6 & & 1 & 1 \\
\hline & $45-54$ & 2 & 2 & 2 & 2 & 3 & 3 & 4 & 5 & 4 \\
\hline & $55-64$ & 3 & 2 & 1 & 2 & 3 & 2 & 5 & 6 & 5 \\
\hline \multicolumn{2}{|l|}{ Day/night shift } & $16 / 2$ & $12 / 1$ & $9 / 3$ & $13 / 3$ & $13 / 0$ & $12 / 1$ & $11 / 0$ & $12 / 2$ & $10 / 1$ \\
\hline Years of & $<1$ & 1 & & & & & & & & \\
\hline health care & $1-10$ & 2 & 2 & 2 & 5 & 3 & 4 & 2 & 1 & 2 \\
\hline experience & $>10$ & 15 & 11 & 10 & 11 & 10 & 9 & 9 & 13 & 9 \\
\hline \multicolumn{2}{|c|}{ Missing data } & 1 & & & & & & & & \\
\hline \multicolumn{2}{|c|}{ Challenge } & 2.13 & 2.65 & 2.42 & 2.03 & 1.86 & 1.65 & 2.02 & 1.89 & 1.82 \\
\hline Innov.org. & Stagna.org & (0.69) & $(0.55)$ & $(0.56)$ & $(0.50)$ & $(0.46)$ & $(0.45)$ & $(0.29$ & $(0.30)$ & $(0.47)$ \\
\hline 2.38 & 1.63 & & & & & & & & & \\
\hline \multicolumn{2}{|c|}{ Freedom } & 1.72 & 1.94 & 2.00 & 1.79 & 1.74 & 1.69 & 1.76 & 1.98 & 1.96 \\
\hline Innov.org. & Stagna.org & $(0.36)$ & $(0.59)$ & $(0.40)$ & $(0.32)$ & $(0.45)$ & $(0.41)$ & $(0.40)$ & $(0.49)$ & $(0.65)$ \\
\hline 2.10 & 1.53 & & & & & & & & & \\
\hline \multicolumn{2}{|c|}{ Idea support } & 1.74 & 2.25 & $2.37^{*}$ & 1.95 & 1.72 & 1.37 & 1.87 & 1.78 & 1.80 \\
\hline Innov.org. & Stagna.org & $(0.75)$ & $(0.79)$ & $(0.59)$ & $(0.69)$ & $(0.61)$ & $(0.63)$ & $(0.34)$ & $(0.70)$ & $(0.66)$ \\
\hline 1.83 & 1.08 & & & & & & & & & \\
\hline \multicolumn{2}{|c|}{ Trust } & 1.69 & 2.05 & 2.16 & 1.56 & 1.45 & 1.03 & 1.87 & 1.76 & 1.96 \\
\hline Innov.org. & Stagna.or & $(0.84)$ & $(0.84)$ & $(0.51)$ & $(0.67)$ & $(0.54)$ & $(0.68)$ & $(0.30)$ & $(0.69)$ & $(0.59)$ \\
\hline 1.78 & 1.28 & & & & & & & & & \\
\hline \multicolumn{2}{|c|}{ Dynamism } & 2.00 & 2.50 & 2.45 & 1.76 & 1.68 & 1.48 & 1.95 & 1.85 & 1.69 \\
\hline Innov.org. & Stagna.org & $(0.71)$ & $(0.61)$ & $(0.63)$ & $(0.63)$ & $(0.45)$ & $(0.44)$ & $(0.34)$ & $(0.46)$ & $(0.55)$ \\
\hline 2.20 & 1.40 & & & & & & & & & \\
\hline \multicolumn{2}{|c|}{ Playfulness } & 2.55 & 2.55 & 2.58 & 1.95 & 1.95 & 1.83 & 1.98 & 1.98 & 2.05 \\
\hline Innov.org. & Stagna.org & $(0.73)$ & $(0.73)$ & $(0.55)$ & $(0.56)$ & $(0.56)$ & $(0.57)$ & $(0.59)$ & $(0.59)$ & $(0.69)$ \\
\hline 2.30 & 1.40 & & & & & & & & & \\
\hline \multicolumn{2}{|c|}{ Debates } & 1.66 & 2.10 & 2.08 & 1.74 & 1.66 & 1.58 & 1.67 & 1.65 & 1.64 \\
\hline Innov.org. & Stagna.org & $(0.53)$ & $(0.64)$ & $(0.57)$ & $(0.43)$ & $(0.42)$ & $(0.34)$ & $(0.22)$ & $(0.44)$ & $(0.62)$ \\
\hline 1.58 & 1.05 & & & & & & & & & \\
\hline \multicolumn{2}{|c|}{ Conflicts } & 0.98 & 0.58 & 0.38 & 0.86 & 1.11 & 1.49 & 0.73 & 0.77 & 0.82 \\
\hline Innov.org. & Stagna.org & $(0.94)$ & $(0.88)$ & $(0.45)$ & $(0.61)$ & $(0.67)$ & $(0.97)$ & $(0.40)$ & $(0.45)$ & $(0.53)$ \\
\hline 0.78 & 1.40 & & & & & & & & & \\
\hline \multicolumn{2}{|c|}{ Risk taking } & 1.52 & 1.98 & 1.90 & 1.39 & 1.48 & 1.15 & 1.33 & 1.29 & 1.29 \\
\hline Innov.org. & Stagna.org. & $(0.56)$ & $(0.57)$ & $(0.56)$ & $(0.44)$ & $(0.38)$ & $(0.45)$ & $(0.38)$ & $(0.48)$ & $(0.65)$ \\
\hline 1.95 & 0.53 & & & & & & & & & \\
\hline \multicolumn{2}{|c|}{ Idea time } & 1.24 & $2.08^{* *}$ & $2.15^{*}$ & 1.51 & 1.46 & 1.25 & 1.56 & 1.52 & 1.33 \\
\hline Innov.org. & Stagna.org & $(0.68)$ & $(0.69)$ & $(0.53)$ & $(0.49)$ & $(0.55)$ & $(0.42)$ & $(0.45)$ & $(0.52)$ & $(0.56)$ \\
\hline 1.48 & 0.97 & & & & & & & & & \\
\hline
\end{tabular}

*Significant at $\leq 0.05 ;{ }^{* *}$ Significant at $\leq 0.01$ within nursing home. Registered nurse (RNs), Licensed Practical Nurses (LPNs), Nurse Aides (NAs), Social service (SS). 
Table 2. Caregivers at NH I-III and their response rate on MBI with mean values and standard deviations (SD) versus normative data on low, average and high burnout according to Maslach et al. [18].

\begin{tabular}{|c|c|c|c|c|c|c|c|c|c|c|c|}
\hline & & & \multicolumn{3}{|c|}{ I } & \multicolumn{3}{|c|}{ II } & \multicolumn{3}{|c|}{ III } \\
\hline & & & & 12 & 24 & & 12 & 24 & & 12 & 24 \\
\hline & & & Baseline & month & month & Baseline & month & month & Baseline & month & month \\
\hline & & & $\mathrm{n}=13$ & $\mathrm{n}=13$ & $\mathrm{n}=10$ & $\mathrm{n}=16$ & $\mathrm{n}=13$ & $\mathrm{n}=13$ & $\mathrm{n}=10$ & $\mathrm{n}=14$ & $\mathrm{n}=11$ \\
\hline \multicolumn{12}{|c|}{ Caregivers } \\
\hline \multicolumn{3}{|c|}{ RNs and LPNs } & $0 / 10$ & $1 / 11$ & $1 / 9$ & $0 / 7$ & $0 / 6$ & $0 / 6$ & $0 / 2$ & $0 / 2$ & $0 / 2$ \\
\hline \multicolumn{3}{|c|}{ NAs and SS } & $2 / 0$ & $1 / 0$ & $0 / 0$ & $8 / 1$ & $6 / 1$ & $6 / 1$ & $8 / 0$ & $12 / 0$ & $9 / 0$ \\
\hline \multicolumn{3}{|c|}{ Female/male } & $12 / 0$ & $12 / 0$ & $8 / 2$ & $15 / 1$ & $12 / 1$ & $11 / 2$ & $10 / 0$ & $14 / 0$ & $11 / 0$ \\
\hline \multirow{4}{*}{\multicolumn{2}{|c|}{ Age (years) }} & $18-34$ & 4 & 3 & 2 & 4 & 3 & 2 & 1 & 2 & 1 \\
\hline & & $35-44$ & 4 & 6 & 6 & 8 & 5 & 6 & & 1 & 1 \\
\hline & & $45-54$ & 1 & 2 & 2 & 2 & 3 & 3 & 4 & 6 & 4 \\
\hline & & $55-64$ & 3 & 2 & & 2 & 2 & 2 & 5 & 5 & 5 \\
\hline \multicolumn{3}{|c|}{ Day/night shift } & $10 / 2$ & $12 / 1$ & $8 / 2$ & $13 / 3$ & $12 / 1$ & $12 / 1$ & $10 / 0$ & $12 / 2$ & $10 / 1$ \\
\hline \multicolumn{2}{|c|}{ Years of } & $<1$ & 1 & & & & & & & & \\
\hline \multicolumn{2}{|c|}{ health care } & $1-10$ & 2 & 2 & 2 & 5 & 2 & 4 & 1 & 2 & 2 \\
\hline \multicolumn{2}{|c|}{ experience } & $>10$ & 9 & 11 & 8 & 11 & 11 & 9 & 9 & 12 & 9 \\
\hline \multicolumn{3}{|c|}{ Missing data } & 1 & & & & & & & & \\
\hline \multicolumn{3}{|c|}{ Emotional exhaustion } & 23.08 & 17.46 & 15.78 & 12.12 & 14.38 & 12.31 & 12.40 & 12.86 & 8.55 \\
\hline Low & Average & High & (7.18) & $(10.52)$ & $(10.61)$ & $(7.97)$ & $(7.73)$ & $(9.46)$ & $(7.53)$ & $(9.16)$ & (6.95) \\
\hline $0-16$ & $17-27$ & $28+$ & & & & & & & & & \\
\hline \multicolumn{3}{|c|}{ Depersonalization } & 3.85 & 3.46 & 2.30 & 1.31 & 2.77 & 2.23 & 3.40 & 2.71 & 2.82 \\
\hline Low & Average & High & (3.65) & $(2.57)$ & $(4.74)$ & $(1.85)$ & $(1.96)$ & $(2.01)$ & (3.17) & $(3.00)$ & (3.63) \\
\hline $0-5$ & $6-10$ & $11+$ & & & & & & & & & \\
\hline \multicolumn{3}{|c|}{ Personal accomplishment } & 40.46 & 40.62 & 42.33 & 37.31 & 35.08 & 31.62 & 37.50 & 32.50 & 38.09 \\
\hline Low & Average & High & (5.94) & $(7.45)$ & (8.79) & $(7.80)$ & $(7.79)$ & $(8.06)$ & (5.13) & $(13.40)$ & (13.46) \\
\hline $37+$ & $30-36$ & $0-29$ & & & & & & & & & \\
\hline
\end{tabular}

Registered Nurse (RNs), Licensed Practical Nurses (LPNs), Nurse Aides (NAs), Social service (SS).

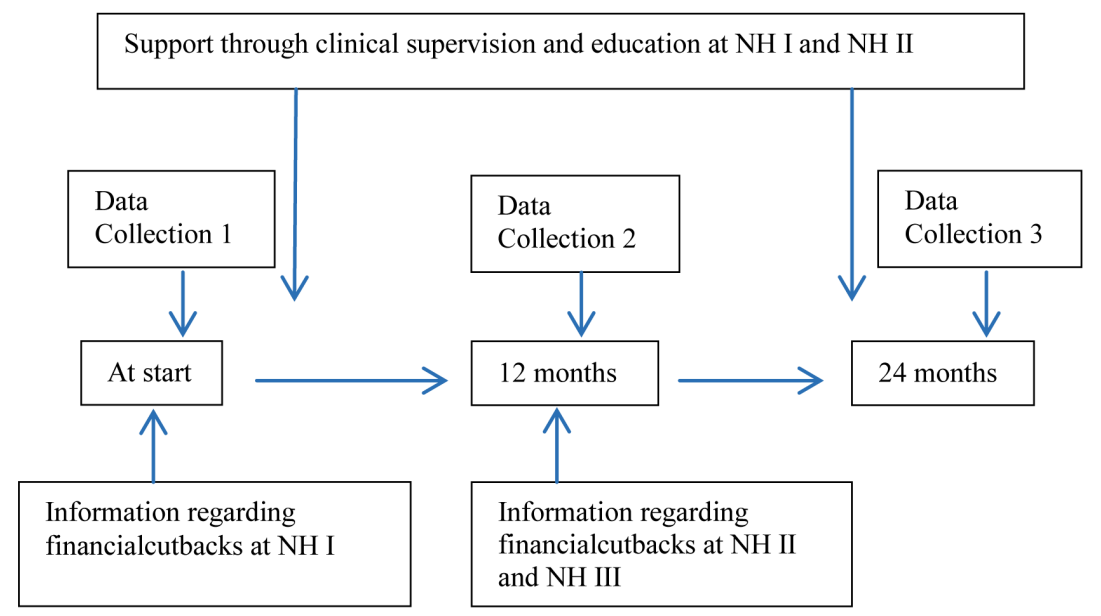

Figure 1. Design of the study and time frame for information regarding financial cutbacks at the respective nursing homes, NH I, NH II and NH III. 


\subsection{Self-Assessment Questionnaires}

The self-assessment questionnaires were distributed three times: before the intervention (baseline) and after 12 and 24 months, respectively. The completed questionnaires were returned individually in postage-paid envelopes addressed to the research team. Two different instruments of Lickert type were used: the Creativity and Innovative Climate Questionnaire (CCQ) [21] and the Maslach Burnout Inventory (MBI) [18].

\subsubsection{Creativity and Innovative Climate Questionnaire}

The CCQ is a self-assessment instrument, earlier used in Sweden [26]-[28] for measuring the degree of creativity and innovativeness in an organization. The CCQ contains 50 items covering 10 dimensions: challenge; freedom; idea support; trust/openness; safety dynamics/liveliness; playfulness/humour; debates; conflicts; risk-taking; idea-time [22]. Each dimension includes five statements assessed on a four-point Likert scale from absolutely not applicable (0) to applicable to some extent (1), fairly applicable (2) and highly applicable (3). The points for these five statements are added up and then divided by the number of statements. The dimensions were developed in connection with several large-factor analytic studies. The stability and internal consistency reliability have been tested and are considered high [22]. Mean reference values for innovative and stagnated organizations are presented in Table 1 . The instrument is described as being an organizational rather than individual measure, as changes are measured at the organizational level [22]. The mean value in each dimension can vary from a strong and dynamic (3.0) to an extremely weak and stagnating organization (0.0). The scales are not reciprocally calibrated, for example the value 2.0 in one dimension is not necessarily higher than 1.5 in another. Comparisons can only be made dimension by dimension. Cronbach's alpha reliability coefficient for the CCQ subscales in the present study is 0.85 .

\subsubsection{Maslach Burnout Inventory}

MBI has become one of the most widely used and validated instruments for assessing burnout and was translated into Swedish by Hallsten [29]. The scale consists of 22 items divided into three subscales. The first subscale, Emotional Exhaustion (EE), uses nine items to assess "feelings of being emotionally overextended and exhausted by one's work". Depersonalization (DP), another subscale, consists of five items and assesses "unfeeling and impersonal response towards recipients of one's care". The Personal Accomplishment (PA) subscale, with eight items, assesses "feeling of competence and successful achievement in one's work with people" [18] [30]. The MBI is scored on a 7-point scale from never (0) to every day (6). Responses are summed to give separate scores for each of the three subscales and are categorized into low, average or high degrees of burnout according to normative data presented in Table 2 [18]. High levels of EE and DP and low levels of PA are associated with burnout. The reliability coefficient for the MBI subscale in the present study was 0.75 .

\subsection{Interviews}

The caregivers at the three NHs were interviewed at the start, after 12 months and after 24 months, giving in total $30+21+13$ interviews at NH I, $16+11+17$ interviews at NH II and $18+19+13$ interviews at NH III. The individual interviews lasted 30 - 60 minutes and took place in a setting chosen by the interviewees, where there would be no interruptions. They were asked about their expectations and experiences of work at the $\mathrm{NH}$ and were encouraged to speak freely about the joys and difficulties of their working situation as well as how they envisioned the future. To investigate changes over time the same questions were asked at all three occasions. To clarify and develop the content of what the interviewees said, questions such as "please tell me more about this situation" or "can you tell me more about how you felt about that situation" were asked cf. [31]. The interviews were tape-recorded with the participants' permission and transcribed verbatim by an experienced secretary. For the present study, five interviews were chosen at random from each interview occasion within the three groups of caregivers ( $5 \times 3$ from NH I- III), which resulted in a total of 45 interviews.

\subsection{Data Analysis}

\subsubsection{Quantitative Data}

Because the sample was small and those taking part were not always the same at the three data-collection points, group mean scores rather than individual scores have been used in the quantitative data analysis. Further, the 
Kruskal-Wallis non-parametric method was used to analyse the differences within the three independent NHs at baseline and both follow-up measurements. Descriptive analysis using means and standard deviations was used for all responses. When significant differences emerged, the Mann-Whitney U-test was used [32]. The analyses were carried out using the SPSS computer program (SPSS, version 17). Because a $P$ value of $\leq 0.05$ was considered statistically significant, the majority of the results were not significant. When the quantitative analyses were finalized it appeared that the results were statistically weak due to the number of drop outs. Thus, qualitative analyses were deemed important to explore how the caregivers expressed the domains in the scales.

\subsubsection{Qualitative Data}

The interviews were analyzed by two of the authors who had not performed the interviews and the procedure was a directed content analysis [33], using the 10 dimensions in CCQ and the three subscales in MBI as a raster. All text from the three interview periods were read several times and coded immediately using the predetermined codes [33]. Notes were made indicating whether and how the interviews changed over time dependent on occurrences and intensity. To validate the outcome, all authors discussed the findings until a consensus was reached.

\section{Results}

Results from interviews and caregivers' self-assessments will be presented and described separately for the respective NHs. The numbers of included caregivers from the three NHs with their response rate of CCQ are presented in Table 1 and Figure 2(a), Figure 3(a) and Figure 4(a). MBI scores are presented in Table 2 and Figure 2(b), Figure 3(b), and Figure 4(b).

\subsection{NH I}

\subsubsection{Creative Climate Questionnaire}

The majority of the baseline scores from the CCQ demonstrated that NH I functioned at the innovative organizational level and an improvement from baseline was seen, which suggests a more innovative organization. The scores for "conflict" and "trust" improved at NH I (Table 1, Figure 2(a)).

\subsubsection{Maslach Burnout Inventory}

The scores from the MBI measurement in NH I did not suggest burnout, but the degree of burnout changed for the better. The caregivers estimated their symptom as average in the EE subscale at baseline, but demonstrated more favourable scores after 24 months. In the PA subscale, the caregivers at NHI estimated favourable scores throughout the study (Table 2, Figure 2(b)).

\subsubsection{Interviews}

The first interviews showed that conflicts were prevalent in the personnel group due to different opinions about prioritizing work and indecisive leadership. Challenges were seen with their expectations of something new, and there was a foreboding that the implementation of new ideas would be limited due to lack of time and support from management. The interviews showed a high degree of emotional frustration among the caregivers. "It was going to be so new and great here. But we don't get on and there's always some argument among the staff. You don't work in the same way. What's worse is that nobody deals with it. The manager says we have to accept that it takes time to start something new, but I mean really we can't continue like this".

The second interviews showed that conflicts still existed among the caregivers as well as frustrations over the weak leadership. Several of the personnel had quit and a lack of dynamics existed due to untrained and insecure replacements. They reported that several in the personnel group had been on sick leave for a shorter or longer period due to emotional distress or exhaustion. The caregivers expressed exhaustion, fatigue and resignation. They tried to do their job, but had no creative ideas or solutions for developing the care they were giving at work. The caregivers felt unable to fully utilize their competence in their work and felt that they worked without planning. The conflicts and lack of time created a lack of freedom. "I've never been at a workplace as bad as this one and we don't have any leadership. One after the other quits or gets burned out. I have no use for my education here. You can't plan and do activities and you don't have time for anything because you never know what your day will be like". 


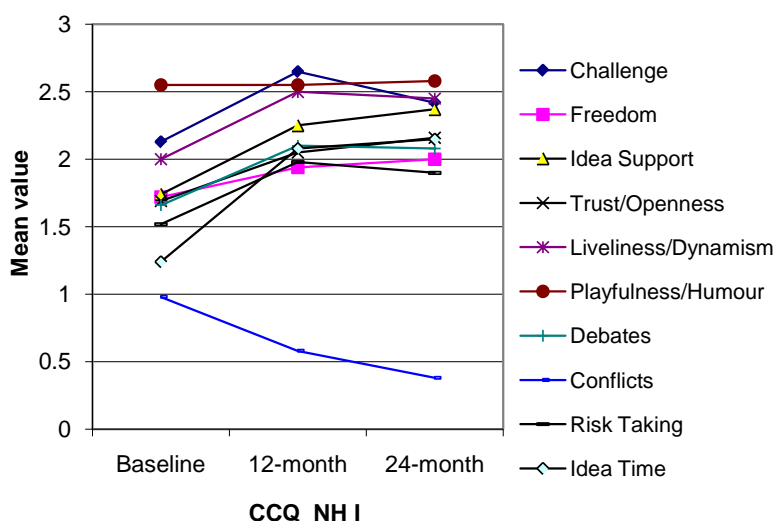

(a)

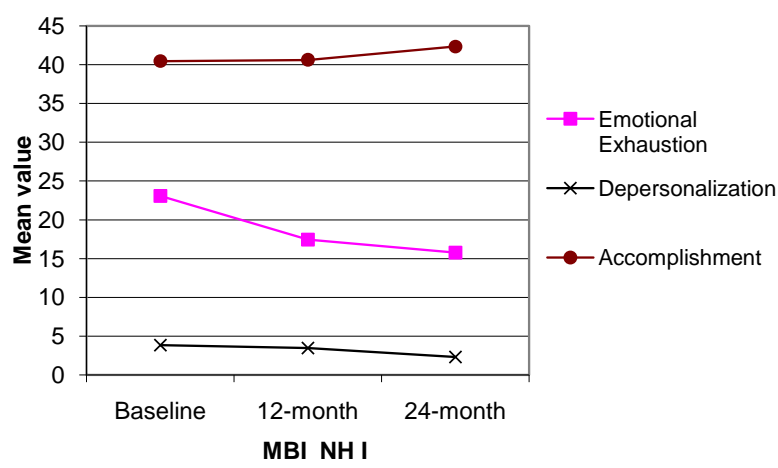

(b)

Figure 2. (a) Caregivers' (NH I) response rate from CCQ with mean values. High values (except conflicts) are representative of a more positive climate; (b) Caregivers' (NH I) response rate from MBI with mean values. Low values (except accomplishment) are representative of a more favourable score.

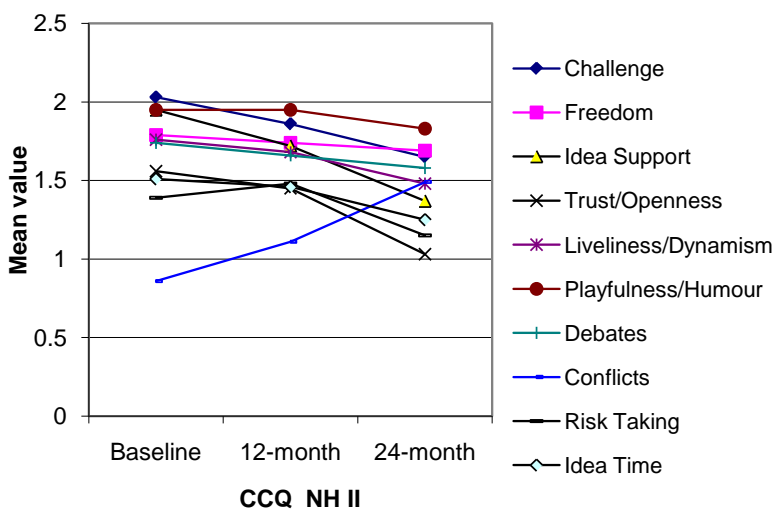

(a)

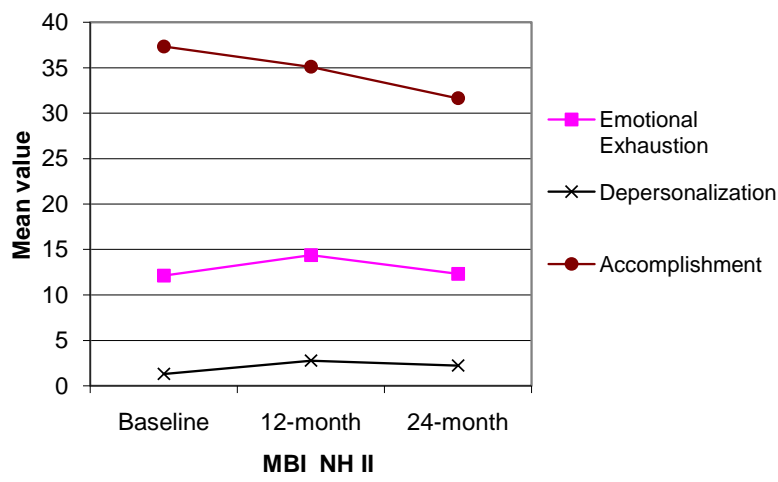

(b)

Figure 3. (a) Caregivers' (NH II) response rate from CCQ with mean values. High values (except conflicts) are representative of a more positive climate; (b) Caregivers' (NH II) response rate from MBI with mean values. Low values (except accomplishment) are representative of a more favourable score.

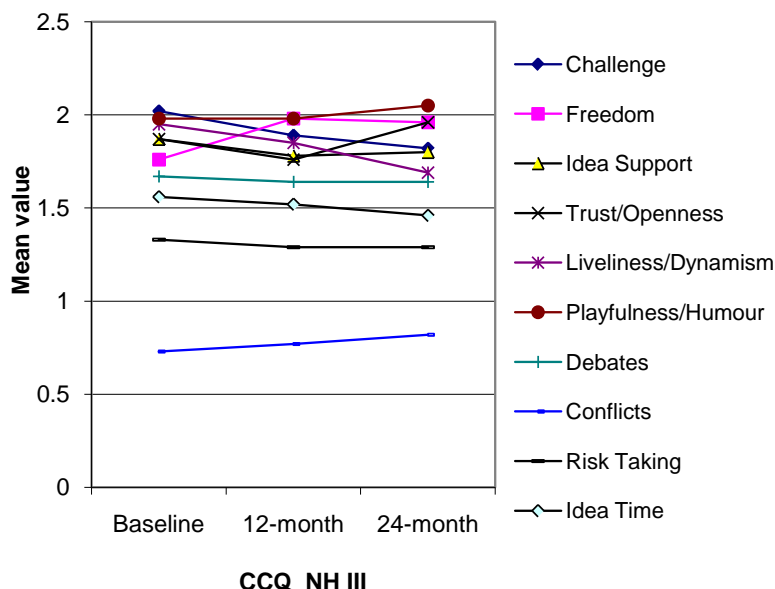

(a)

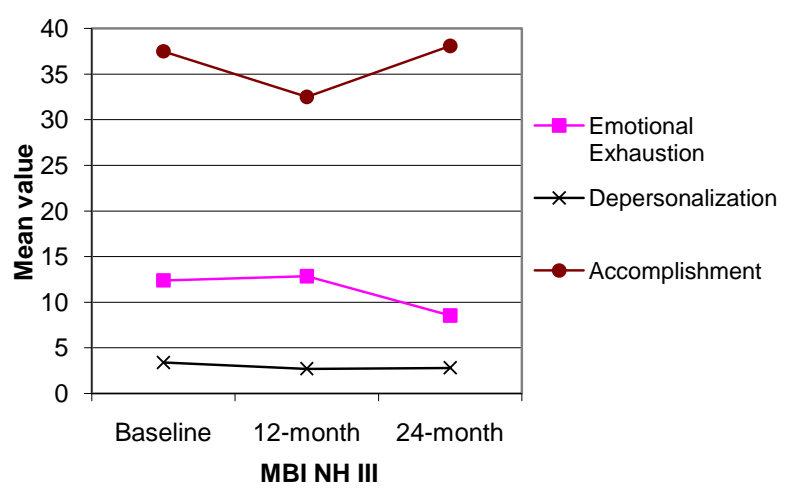

(b)

Figure 4. (a) Caregivers' (NH III) response rate from CCQ with mean values. High values (except conflicts) are representative of a more positive climate; (b) Caregivers' (NH III) response rate from MBI with mean values. Low values (except accomplishment) are representative of a more favourable score. 
The third interviews showed that many in the primary work group had left their employment. The remaining caregivers attempted to find new challenges and possibilities in their work. The interviews indicated an ability among the caregivers to tolerate uncertainty and disparity, despite the conflicts that still existed due to poor leadership. The personnel had divided themselves into informal groups attempting to support each other. They used playfulness and humour and avoided discussions in an effort to cope with their work. Some said they could cope with the work situation because they "did not care" or "just didn't think about it". "Our expectations were much higher than how things turned out. Dementia care here was going to be really super, but that hasn't happened. There's been quite a bit of friction, but things have got better. We try to stick together and laugh about the craziness, otherwise you can't cope. Of course it's always so that you don't like everybody, but what does that matter? I don't care about things like that, as long as you can work together".

\subsection{NH II}

\subsubsection{Creative Climate Questionnaire}

The caregivers from NH II had scores that progressed negatively from baseline to the 24-month follow up. Some of the scores suggested stagnation in the organization. The scores for "conflict" and "trust" worsened over the period (Table 1, Figure 3(a)).

\subsubsection{Maslach Burnout Inventory}

The caregivers from NH II had a low mean score on DP and EE, which changed after 12 months, but still indicated a low degree of burnout. NH II had a mean score at 24 months on the PA subscale that was considered “average” (Table 2, Figure 3(b)).

\subsubsection{Interviews}

The first interviews showed that challenge, freedom and playfulness were prevalent, with positive feelings and expectations regarding their new work. The caregivers felt they had idea-support from management when they were given the opportunity to implement a positive milieu for themselves and the older people and they showed independence in their decisions. Time was available to work on new ideas and the climate suggested easiness in the workplace atmosphere. The relationship with colleagues and the residents showed emotional involvement with security. Nevertheless some anxiety existed about the unfamiliar milieu due to the vast physical layout of the NH. "I try to do my best for the residents so they will thrive. Meet their needs to the extent I can".

After one year, the interviews showed uncertainty, and the caregivers' trust and openness with regard to the management had decreased. There were increasing conflicts in work groups, and the freedom and independence in decision-making that was seen in the first interviews was no longer prominent. From having been focused on their work, the personnel were now more focused on their individual situations. Nevertheless, they still had hope that they could continue to influence their work and some emotional involvement still existed. "We've heard rumors that another facility will be closed and that more residents will come here without any increase in staff. What happened to everything they promised us, for example, that we'd be part of a project, get supervision and support? Do we dare believe that we can continue as we planned and as we were promised"?

Emotional involvement and trust in management were not prominent in the third interviews, and the caregivers were more watched over in their work. They were frustrated about conflicts that existed in the groups and the lack of idea-support. Signs of fatigue and exhaustion now appeared in the interviews when the caregivers described their work as more hectic. They realized that their expectations of giving good care would not been fulfilled, but they were not willing to give up. "What's missing is a discussion about what duties we should have in relation to the staff we are. Now we're supposed to clean, do laundry, take care of purchasing, call in staff and give residents personal care, food and such, but does the individual older person have a right to individual time”?

\subsection{NH III}

\subsubsection{Creative Climate Questionnaire}

The scores from NH III were stable throughout the study, however half of the CCQ dimensions demonstrated less favourable conditions at the 24-month follow-up. The scores for "conflict" and "trust" remained stable (Table 1, Figure 4(a)). 


\subsubsection{Maslach Burnout Inventory}

In the EE and PA subscales from NH III, the mean scores worsened at 12 months, but eventually improved from baseline after 24 months (Table 2, Figure 4(b)).

\subsubsection{Interviews}

The first interviews showed that trust, safety dynamics and playfulness predominated. The caregivers were preoccupied with their work and showed self-confidence when describing a workplace that was familiar to them. They knew their colleagues and management well and did not feel tension in their work groups. They showed pride when describing that the residents and management appreciated them. The atmosphere was relaxed, even though there was a great deal of work to do and sometimes no time for doing that "little extra". "I think it works fine, we can bring up problems, new suggestions and we often get responses to what we bring up. We're going to change the schedule and food provision, and I think that's good. Our supervisor lets us decide more and more for ourselves how we want to work".

After one year, the interviewees expressed feelings of insecurity and increasing conflict. Their degree of freedom was reduced by the changes that had occurred. Not knowing where to go in the morning, which residents they would be responsible for or with whom they would work created the feeling they were losing control. The tension in the work groups was increasing and they felt forced to cooperate. The playfulness and humour present in the first interview was not prominent, and they missed colleagues who had left. The discussions about reduction and termination notices filled their days, and according to the caregivers, these had given rise to an unpleasant atmosphere. "Now we think there's no reason for us after knowing we're going to be closed downwell we do what has to be done, nothing more, and I feel dissatisfied with not being able to plan my work".

Resignation was shown in the third interviews, and the caregivers talked about making the best of the situation. They were safeguarding themselves and the residents. Conflicts and irritations existed in the work groups. Lack of commitment was seen when they described the discussions about planning their work. Nevertheless, their feelings of responsibility for the residents, a belief in the future or in new work made them continue to struggle. The appreciation they received from the residents, relatives and management helped them carry out their work. "I wouldn't have anything against leaving this place, the work situation is insecure. In elder care there must be people who are interested and there must be commitment to working with the old people. As it is now it's difficult to feel motivated. You can't lose your patience when you work with old people".

\section{Discussion}

The present mixed methods study investigates consequences experienced over time by the caregivers at three NHs when organizational changes are an actuality; and when caregivers at two of these NHs received support. Interesting findings include the negative outcome from both assessment instruments and the interviews at all three NHs when they were anticipating and undergoing organizational changes and cutbacks (Figure 1). Cutbacks appeared to cause much stress and frustration among the personnel groups, and they felt guilty about not fulfilling their perceived obligations. The caregivers from all three NHs gave the impression of continuing to struggle, but seemed to have lost something important: their pride in giving good care. Juthberg et al. [34] have described similar results in a study; not being able to provide the care residents need, experiencing shortcomings and caregivers having to silence one's conscience in order to continue working. Likewise stress from a troubled conscience can lead to emotional exhaustion and a risk for burnout [35]. Jones [36] concluded that clinical supervision challenges nurses to think differently about their professional work. This has also been highlighted as a possible strategy for recruitment and retention within all levels of nursing personnel [37]. Therefore, supervision can help nurses to achieve a number of valuable objectives. In a literature review, Butterworth et al. [38] found that most clinical supervision was seen as an educative and supportive process, in addition they also found in some studies that clinical supervision can be cost-effective and improve care.

NHs I and II received support through education and clinical supervision for two years, but the outcome with regard to their scores was different. The scores at NH III were more constant compared with the others. The announcement of planned cutbacks and their realization may have been mirrored in the scores. The support provided in the present study seemed to have helped the caregivers at NH I, but was not able to alter the situation for caregivers at NH II, who were informed of the changes later in the study. A second analysis of all NH II interviews was reported by Fläckman et al. [25], with the conclusion that after two years the caregivers' willingness to care continued, despite their disappointment in the worsened working conditions. The main theme that 
resulted was that despite shattered expectations, a willingness to care for older people remained. The continued education and clinical supervision seem to be one factor behind this continued commitment. These findings demonstrate that support and caregiver involvement in educational programs are important during times of change and when disappointments arise in the workplace. Other aspects such as the work climate and support and inclusion of all those that work in the nursing homes are also important when education and clinical supervision are offered to produce good outcomes [39].

At NHs II and III, the MBI scores worsened at the 12-month assessment, which corresponded to the time when they began discussing financial cutbacks (Figure 1). The 24-month scores improved for "feelings of competence and successful achievement in one's work" at NH III. By that time, the personnel at NH III were familiar with the plan for staff reduction. Research regarding the correlations and a manifestation of burnout is quite difficult to interpret because the theories vary a great deal and the research findings often contradict each other [40] [41]. Different patterns of possible causes and consequences imply that different intervention strategies need to be used [42].

The interviews from NH I-II revealed a disappointment with the leadership and the staffs there were not as stable as those at NH III who were more pleased with their leaders. Hannigan et al. [43] revealed that poor support from management was associated with higher emotional exhaustion and that longer work experience in a field was associated with lower depersonalization scores. This is consistent with the BMI result of NH I in this study. Hyrkäs et al. [44] claimed that even first-line leaders need support in their work. Several organizational changes and scarce economic resources in the health care system have also challenged nursing leaders.

Using a quantitative design, Edwards et al. [45] found a lower level of burnout among community mental health nurses when clinical supervision was effective. Similarly, Begat and Severinsson [46] reported that clinical supervision had an influence on nurses' experiences of well-being. Based on a quantitative design, Choi and Johantgen [47] showed that supportive supervision was important for job satisfaction among certified nursing assistants in nursing homes. This confirmed findings reported by Hyrkäs [44] and Hyrkäs et al. [48] who also found that levels of stress decreased when supervision was available.

In a creative climate, organization members are emotionally involved in their work [22]. Furthermore, a question can be raised about the nursing care quality during the two-year period. According to Ekvall [21], the work climate influences organizational processes such as problem-solving, decision-making, communication, co-ordination and control. Providing care in the context of organizational change can lead to conflicts between what the employee is being asked to do and the employee's knowledge and competences. Creative work climate has a strong relationship to job satisfaction [49]. The present study followed the personnel group over time from an organizational rather than an individual perspective, which is in accordance with Ekvall [22]. The results presented in the present study have similarities with Trydegård [2] indicating that changes have not been appreciated.

\section{Study Limitations}

In this study due to reorganizations and cut backs the quantitative research originally intended was not possible; so a mixed method design was chosen. Changes are common in elder care [1]-[5] and there is much that can interfere and influence ongoing research projects. This can be seen as a challenge for future research in elder care especially for longitudinal studies. A mixed method that included a combination of methods was chosen to meet this challenge, add strength to the study and facilitate a deeper understanding into the experiences of caregivers of older people. Data from the qualitative analysis provided insights and facilitated interpretation of statistical findings based on the self-assessment instruments [50]. The approach also provided an opportunity to maximize the richness of the narratives [51]. The divergent results in the quantitative and qualitative data among caregivers in NH I are interesting. One question is whether questionnaires are sensitive enough to capture the necessary dimensions in an organizational climate. The present findings demonstrate, however, how the use of mixed methods [24] can lead to accounts that strengthen and/or complement each other. One contributory factor may also be lack of time needed to respond to and reflect on the questions in the questionnaires. Another issue is what kind of situations the caregivers assessed and what kind of situations they reported. The questionnaires were directed towards the work climate, and the interviews were more focused on the work situation as a whole. In the interviews, most of the frustrations expressed were over the leadership, which the assessment scales did not capture. This can be understood in that the leader and their leadership are more important than the staff as individuals when change is to be executed [12]. 
The interviews were analyzed by two of the authors who had not performed the interviews. In the present study, this can be viewed as a strength, as the authors were able to consider the interviews as a whole and without any pre-understandings based on the interview situations or earlier analyses of quantitative data. The personnel groups were largely comparable. NHs II and III were, however, located in a smaller municipalities than NH I, which may have limited staff members' opportunities for job change. This may have affected the results as well as the structural changes and reductions in staff due to political decisions. During an intervention period of two years, many unexpected events can occur, as was the case in the present study. The unplanned changes in the NHs, due to the organizational changes and uncontrolled factors influencing the study, created another threat to internal validity [52].

\section{Conclusions and Practical Implications}

The results of the present study showed negative outcomes at all three NHs when the organizational changes and cutbacks were announced. The new situation caused major stress and frustrations among the personnel groups, and they felt guilty about not meeting their perceived obligations. Providing education and clinical supervision during such a time constituted a challenge, but it is interesting to speculate on what would have happened without such an intervention. The present study emphasizes the need for more research in this area to further investigate factors for preventing burnout, improving creativity and innovation in an effort to help people stay in their occupations as caregivers of older people. More research is also needed on how these factors such as reorganization and cutbacks influence person-centered care and the support the staff requires to provide good quality care to older people. Further research is also necessary in the area of the working environment and its effects on recruiting and retaining health care staff in elder care.

\section{Acknowledgements}

The authors wish to express their gratitude to the Swedish Association of Local Authorities in Gävleborg, the Centre for Caring Sciences, Örebro University Hospital and to the University of Gävle for their financial support during the study. Our thanks also go the personnel from the nursing homes for their cooperation and extra efforts.

\section{Contributions}

Study design: AK, BF, KS, MK; data collection: BF; data analysis: AK, BF, KS and manuscript preparation: BF, AK, KS, IF, MK

\section{Conflict of Interest}

No conflict of interest has been declared by the authors.

\section{References}

[1] Dahl, H.M. (2009) New Public Management, Care and Struggles about Recognition. Critical Social Policy, 29, 634654. http://dx.doi.org/10.1177/0261018309341903

[2] Trydegård, G.-B. (2012) Care Work in Changing Welfare States: Nordic Care Workers’ Experiences. European Journal of Ageing, 9, 119-129. http://dx.doi.org/10.1007/s10433-012-0219-7

[3] Dwyer, L.-L., Andershed, B., Nordenfeldt, L. and Ternestedt, B.-M. (2009) Dignity as Experienced by Nursing Home Staff. International Journal of Older People Nursing, 4, 185-193. http://dx.doi.org/10.1111/j.1748-3743.2008.00153.x

[4] Häggström, E., Mamhidir, A.-G. and Kihlgren, A. (2010) Caregiver's Strong Commitment to Their Relationship with Older People. International Journal of Nursing Practice, 16, 99-105. http://dx.doi.org/10.1111/j.1440-172X.2010.01818.x

[5] Suhonen, R., Stolt, M., Virtanen, H. and Leino-Kilpi, H. (2011) Organizational Ethics: A Literature Review. Nursing Ethics, 18, 285-303. http://dx.doi.org/10.1177/0969733011401123

[6] Fagerberg, I. and Engström, G. (2012) Care of the Old-A Matter of Ethics, Organization and Relationship. International Journal of Qualitative Studies on Health and Well-Being, 7, 9684. http://dx.doi.org/10.3402/qhw.v7i0.9684

[7] Petterson, I.-L., Donnersvärd, H.Å., Lagerström, M. and Toomingas, A. (2006) Evaluation of an Intervention Programme Based on Empowerment for Eldercare Nursing Staff. Work and Stress, 20, 353-369. http://dx.doi.org/10.1080/02678370601070489 
[8] Kihlgren, M. and Hansebo, G. (2014) Organizational Change and Supervision. In: Watkins Jr., C. and Milne, D.L., Eds., The Wiley International Handbook of Clinical Supervision, John Wiley \& Sons, Ltd., West Sussex, 155-176. http://dx.doi.org/10.1002/9781118846360.ch7

[9] Berggren, I. and Severinsson, E. (2003) Nurse Supervisors’ Actions in Relation to Their Decision-Making Style and Ethical Approach to Clinical Supervision. Journal of Advanced Nursing, 41, 615-622. http://dx.doi.org/10.1046/j.1365-2648.2003.02573.x

[10] Nilsson, A. and Engström, M. (2015) E-Assessment and an e-Training Program among Elderly Care Staff Lacking Formal Competence: Results of a Mixed-Methods Intervention Study. BMC Health Services Research, 15, 189 http://dx.doi.org/10.1186/s12913-015-0843-y

[11] Berggren, I., Barbosa da Silva, A. and Severinsson, E. (2005) Core Ethical Issues of Clinical Nursing Supervision. Nursing and Health Services, 7, 21-28. http://dx.doi.org/10.1111/j.1442-2018.2005.00224.x

[12] Johansson, G., Andersson, L., Gustafsson, B. and Sandahl, C. (2010) Between Being and Doing-The Nature of Leadership of First-Line Nurse Managers and Registered Nurses. Journal of Clinical Nursing, 19, 2619-2628. http://dx.doi.org/10.1111/j.1365-2702.2010.03211.x

[13] The Swedish National Board of Health and Welfare (2004) Vård och omsorg om äldre—En läges rapport 2004 [Caring for Older People_A Situation Report 2004]. Socialstyrelsen, Stockholm. (In Swedish) http://www.socialstyrelsen.se/publikationer2004/2004-131-5

[14] The Swedish National Board of Health and Welfare (2012) Vård och omsorg om äldre—En läges rapport 2012 [Caring for Older People_-A Situation Report 2012]. Socialstyrelsen, Stockholm. (In Swedish) http://www.socialstyrelsen.se/publikationer2012/2012-2-2

[15] The Swedish National Board of Health and Welfare (2009) Vård och omsorg om äldre—En läges rapport 2009 [Caring for Older People_A Situation Report 2009]. Socialstyrelsen, Stockholm. (In Swedish) http://www.socialstyrelsen.se/publikationer2009/2009-126-44

[16] Josefsson, K. and Hansson, M. (2011) To Lead and to Be Led in Municipal Elderly Care in Sweden as Perceived by Registered Nurses. Journal of Nursing Management, 19, 498-506. http://dx.doi.org/10.1111/j.1365-2834.2011.01228.x

[17] Fagerberg, I. and Gilje, F. (2007) A Comparison of Curricular Approaches of Care of the Aged in Swedish and US Nursing Programs. Nurse Education in Practice, 7, 358-364. http://dx.doi.org/10.1016/j.nepr.2006.11.007

[18] Maslach, C., Jackson, S.E. and Leiter, P. (1996) Maslach Burnout Inventory Manual. Consulting Psychologists Press, Palo Alto.

[19] Ekstedt, M. and Fagerberg, I. (2005) Lived Experiences of the Time Preceding Burnout. Journal of Advanced Nursing, 49, 59-67. http://dx.doi.org/10.1111/j.1365-2648.2004.03264.x

[20] Vinje, H.F. and Mittelmark, M.B. (2007) Job Engagement's Paradoxical Role in Nurse Burnout. Nursing and Health Sciences, 9, 107-111. http://dx.doi.org/10.1111/j.1442-2018.2007.00310.x

[21] Ekvall, G. (1987) The Climate Metaphor in Organization Theory. In: Bass, B. and Drenth, P., Eds., Advances in Organizational Psychology, Sage, Beverly Hills, 177-190.

[22] Ekvall, G. (1996) Organizational Climate for Creativity and Innovation. European Journal of Work and Organizational Psychology, 5, 105-123. http://dx.doi.org/10.1080/13594329608414845

[23] Hertting, A., Nilsson, K., Theorell, T. and Sätterlund Larsson, U. (2004) Downsizing and Reorganization: Demands, Challenges and Ambiguity for Registered Nurses. Journal of Advanced Nursing, 45, 145-154. http://dx.doi.org/10.1046/j.1365-2648.2003.02876.x

[24] Cresswell, J.W. and Plano Clark, V.L. (2007) Designing and Conducting Mixed Method Research. Sage Publications Inc., Thousand Oaks.

[25] Fläckman, B., Fagerberg, I., Häggström, E., Kihlgren, A. and Kihlgren, M. (2007) Despite Shattered Expectations a Willingness to Care for Elders Remains with Education and Clinical Supervision. Scandinavian Journal of Caring Science, 21, 379-389. http://dx.doi.org/10.1111/j.1471-6712.2007.00478.x

[26] Lövgren, G., Rasmussen, B.H. and Engström, B. (2002) Working Conditions and the Possibility of Providing Good Care. Journal of Nursing Management, 10, 201-209. http://dx.doi.org/10.1046/j.1365-2834.2002.00290.x

[27] Norberg, K.-G., Hellzén, O., Sandman, P.-O. and Asplund, K. (2002) The Relationship between Organizational Climate and the Content of Daily Life People with Dementia Living in a Group-Dwelling. Journal of Clinical Nursing, 11, 237-246. http://dx.doi.org/10.1046/j.1365-2702.2002.00579.x

[28] Söderlund, M., Norberg, A. and Hansebo, G. (2014) Validation Method Training: Nurses’ Experiences and Ratings of Work Climate. International Journal of Older People Nursing, 9, 79-89. http://dx.doi.org/10.1111/opn.12027

[29] Hallsten, L. (1985) Burnout. A Study about Adaption and Development Processes in a Bureaucracy [Burnout. En studie kring anpassning och utvecklings processer I en byråkrati]. Rapport 18:2, LAMI Arbetsmarknadsinstitutet, 
Länsarbetsnämnden I Stockholms Läns, Stockholm. (in Swedish)

[30] Maslach, C. and Jackson, S.E. (1981) The Measurement of Experienced Burnout. Journal of Occupational Behaviour, 2, 99-113. http://www.aagbi.org/sites/default/files/Maslach.pdf http://dx.doi.org/10.1002/job.4030020205

[31] Kvale, S. (1997) The Qualitative Research Interview [Den kvalitativa forsknings intervjun]. Studentlitteratur, Lund. (in Swedish)

[32] Polit, D.F. and Beck, C.T. (2008) Nursing Research. Principles and Methods. 7th Edition, Lippincott Williams \& Wilkins, Philadelphia.

[33] Hsieh, H.-F. and Shannon, S.E. (2005) Three Approaches to Qualitative Content Analysis. Qualitative Health Research, 15, 1277-1288. http://dx.doi.org/10.1177/1049732305276687

[34] Juthberg, C., Eriksson, S., Norberg, A. and Sundin, K. (2008) Stress of Conscience and Perceptions of Conscience in Relation to Burnout among Care-Providers in Older People. Journal of Research in Nursing, 17, 1897-1906. http://dx.doi.org/10.1111/j.1365-2702.2007.02184.x

[35] Glasberg, A.L., Eriksson, S. and Norberg, A. (2007) Burnout and “Stress of Conscience” among Healthcare Personnel. Journal of Advanced Nursing, 57, 392-403. http://dx.doi.org/10.1111/j.1365-2648.2007.04111.x

[36] Jones, A. (2006) Clinical Supervision: What Do We Know and What Do We Need to Know? A Review and Commentary. Journal of Nursing Management, 14, 577-585. http://dx.doi.org/10.1111/j.1365-2934.2006.00716.x

[37] Cummins, A. (2009) Clinical Supervision: The Way Forward? A Review of the Literature. Nurse Education in Practice, 9, 215-220. http://dx.doi.org/10.1016/j.nepr.2008.10.009

[38] Butterworth, T., Bell, L., Jackson, C. and Pajnkihar, M. (2008) Wicked Spell or Magic Bullet? A Review of the Clinical Supervision Literature 2001-2007. Nurse Education Today, 28, 264-272. http://dx.doi.org/10.1016/j.nedt.2007.05.004

[39] Nolan, M., Davies, S., Brown, J., Wilkinson, A., Warnes, T., McKee, K., Flannery, J. and Stasi, K. (2008) The Role of Education and Training in Achieving Change in Care Homes: A Literature Review. Journal of Research in Nursing, 13, 411-433. http://dx.doi.org/10.1177/1744987108095162

[40] Schaufeli, W.B. and Buunk, B.P. (1996) Burnout: An Overview of 25 Years of Research and Theorizing. In: Schabracq, M.J., Winnubst, J.A.M. and Cooper, C.L., Eds., Handbook of Work and Health Psychology, John Wiley \& Son Ltd., Chichester, 383-425.

[41] Schaufeli, W.B., Bakker, A.B. and Van Rhenen, W. (2009) How Changes in Job Demands and Resources Predict Burnout, Work Engagement, and Sickness Absenteeism. Journal of Organizational Behavior, 30, 893-917. http://dx.doi.org/10.1002/job.595

[42] Schaufeli, W.B. and Bakker, A.B. (2004) Job Demands, Job Resources, and Their Relationship with Burnout and Engagement: A Multi-Sample Study. Journal of Organizational Behavior, 25, 293-515. http://dx.doi.org/10.1002/job.248

[43] Hannigan, B., Edwards, D., Coyle, D., Fothergill, A. and Burnard, P. (2000) Burnout in Community Mental Health Nurses: Findings from the All-Wales Stress Study. Journal of Psychiatric and Mental Health Nursing, 7, 127-134. http://dx.doi.org/10.1046/j.1365-2850.2000.00279.x

[44] Hyrkäs, K. (2005) Clinical Supervision, Burnout, and Job Satisfaction among Mental Health and Psychiatric Nurses in Finland. Issues in Mental Health Nursing, 26, 531-556. http://dx.doi.org/10.1080/01612840590931975

[45] Edwards, D., Burnard, P., Urnard, P., Hannigan, B., Cooper, L., Adams, J., Juggessur, T., Fothergil, A. and Coyle, D. (2006) Clinical Supervision and Burnout: The Influence of Clinical Supervision for Community Mental Health Nurses. Journal of Clinical Nursing, 15, 1007-1015. http://dx.doi.org/10.1111/j.1365-2702.2006.01370.x

[46] Begat, I. and Severinsson, E. (2006) Reflection on How Clinical Nursing Supervision Enhances Nurses’ Experiences of Well-Being Related to Their Psychosocial Work Environment. Journal of Nursing Management, 14, 610-616. http://dx.doi.org/10.1111/j.1365-2934.2006.00718.x

[47] Choi, J.S. and Johantgen, M. (2012) The Importance of Supervision in Retention of CNAs. Research in Nursing \& Health, 35, 187-199. http://dx.doi.org/10.1002/nur.21461

[48] Hyrkäs, K., Appelqvist-Schmidlechner, K. and Haataja, R. (2006) Efficacy of Clinical Supervision: Influence on Job Satisfaction, Burnout and Quality of Care. Journal of Advanced Nursing, 55, 521-535. http://dx.doi.org/10.1111/j.1365-2648.2006.03936.x

[49] Sellgren, S.F., Ekvall, G. and Tomson, G. (2008) Leadership Behaviour of Nurse Managers in Relation to Job Satisfaction and Work Climate. Journal of Nursing Management, 16, 578-587. http://dx.doi.org/10.1111/j.1365-2934.2007.00837.x

[50] Morgan, D.G. and Stewart, N.J. (2002) Focus on Research Methods, Theory Building through Mixed-Method Evaluation of a Dementia Special Care Unit. Research in Nursing \& Health, 25, 479-488. http://dx.doi.org/10.1002/nur.10059 
[51] Szabo, V. and Strang, V.R. (1997) Secondary Analysis of Qualitative Data. Advances in Nursing Science, 20, 66-74. http://dx.doi.org/10.1097/00012272-199712000-00008

[52] Burns, N. and Grove, S.K. (2001) The Practice of Nursing Research, Conduct, Critique, and Utilization. 4th Edition, W.B. Saunders Company, Philadelphia. 